\title{
Meeting on health workforce observatories in the Eastern Mediterranean Region ${ }^{1}$
}

Citation: Meeting on health workforce observatories in the Eastern Mediterranean Region. East Mediterr Health J. 2018;24(9):965-967 https://doi. $\operatorname{org} / 10.26719 / 2018.24 \cdot 9.965$

Copyright (c) World Health Organization (WHO) 2018. Some rights reserved. This work is available under the CC BY-NC-SA 3.o IGO license (https:// creativecommons.org/licenses/by-nc-sa/3.o/igo).

Across the Eastern Mediterranean Region (EMR) almost all countries are facing challenges related to health workforce status, including personnel shortages, imbalance in distribution, poor performance, safety and security, and migration (1). However, Goal 3 (2) of the Sustainable Development Goals (SDGs) highlights the need for substantial increases in the health workforce recruitment, development, training and retention (3). To this end, the sixty-ninth World Health Assembly endorsed the Global Strategy on Human Resources for Health: Workforce 2030 (GSHRH) (4), and adopted a resolution (WHA69.19) (5) in support of its implementation. Informed by the GSHRH, the EMR has endorsed the Framework for Action for Health Workforce Development (6) to accelerate addressing health workforce challenges.

Access to reliable and updated health workforce information has been a serious gap in the Region (1), which led to the creation of health workforce observatories (7) as a mechanism to improve health workforce information availability, analysis and use for policy-making. Regional and national health workforce observatories provide a platform for sharing and dissemination of information as well as for policy dialogue to strengthen health workforce capacities at the regional and country levels. However, there is a need to review the status of such observatories and reorient their functions in order to strengthen their role in response to health workforce developments.

To this end, a meeting on EMR health workforce observatories to discuss these issues was organized by the WHO Regional Office for the Eastern Mediterranean (WHO/EMRO) in Cairo during October 23-24, 2017, Cairo, Egypt (8). Participants attended from Afghanistan, Egypt, Islamic Republic of Iran, Jordan, Morocco, Oman, Palestine, Saudi Arabia, Sudan, Syrian Arab Republic, Tunisia, United Arab Emirates, as well as representatives from the Organisation for Economic Cooperation and Development (OECD), the USAID funded HRH2030 programme, and other leading experts.

The objectives of the meeting were to:

- review health workforce information challenges in the Region;

- discuss the National Health Workforce Accounts as a tool, including a priority set of indicators to be collected in countries;
- agree on the next steps to strengthen mechanisms, such as health workforce observatories, that ensure adequate collection of data for priority indicators and improving health workforce information; and

- review and agree on future directions of health workforce observatories in the EMR.

The meeting was inaugurated by Dr Zafar Mirza, Director of Health Systems Development, WHO/EMRO, who emphasized the need for national and regional commitments to strengthen health information systems (HIS), in order to ameliorate issues of health workforce production, retention, quality, performance and distribution.

\section{Summary of discussions}

Health workforce information challenges and
developments Despite the major challenge of having incomplete, contradicting or outdated data, some notable improvements were highlighted, including Morocco's development of an evidence-based response to tackle the issue of their aging workforce; Afghanistan's policy development to address rural workforce retention; and the Islamic Republic of Iran's creation of a databank and centre for human resource health $(\mathrm{HRH})$ research within the Ministry of Health to tackle structural problems in data collection. Common challenges remained, including:

- scarcity of and incomplete data

- variation in definitions of health workforce categories

- lack of data on registered and active workforce

- weak data on attrition, international mobility and unemployment

- absence of complete information on private sector health workforce

- discrepancies between data producers and duplications in reported numbers

- $\quad$ under-developed digitalized records and databases in certain countries

- lack of transparency between HRH stakeholders and political divisions.

\footnotetext{
This report is extracted from the Summary report on the meeting on health workforce observatories in the Eastern Mediterranean Region. Cairo: WHO/EMRO; 2017 (http://applications.emro.who.int/docs/IC_Meet_Rep_2018_EN_16777.pdf).
} 


\section{National Health Workforce Accounts}

WHO has initiated National Health Workforce Accounts (NHWAs) as a tool to strengthen health workforce information through facilitating standardization and comparability of health workforce information systems for interoperability and to support tracking health workforce policy and performance. The NHWA consists of a handbook detailing 78 indicators in 10 modules, implementation guide and on-line platform. NHWA offers a set of indicators that can help countries identify appropriate and feasible indicators to monitor their health workforce.

\section{Defining information required}

Discussions focused on identifying priority health workforce indicators by reviewing strategic objectives and their corresponding monitoring and evaluation indicators from the Regional Framework for Action. In addition to these indicators, participants debated the addition of a number of disaggregates for certain indicators such as gender, geographic distribution, expenditure on private education or resignation from the public sector. It was noted that most indicators were qualitative in nature, but must be translated into quantitative measures for data collection, monitoring and evaluation at the country level.

\section{Sourcing information}

In light of the identified priority indicators, it was emphasized that significant data would be required. An overview was provided on the importance of investing in data collection systems, data management standards, governance, infrastructure, support and dissemination for data use. Additionally, identifying partners and institutions that produce or use health workforce data, improving data generation and building capacity for data collection are important in strengthening health workforce information.

\section{Health workforce observatories as a mechanism for data sourcing and maintenance}

Health workforce observatories have been used globally as a mechanism to improve health workforce information and evidence research over the last decade. Country experiences have indicated that having strengthened health workforce information was an essential building block for developing evidence-based HRH policies to address quality, performance, accessibility, acceptability and availability of information. Thus, health workforce observatories serve as platforms for policy analysis, research, dialogue and advocacy.

\section{Future direction of health workforce observatories}

In order to have effective and sustainable health workforce observatories, participants identified the importance of having political commitment, stakeholder collaboration, and sustainable financial resources. Additionally, participants evaluated observatories with regards to their function, organization and regulation. With regards to leadership and coordination of the observatories, a national forum or steering board, headed by the ministry of health, needs to be instituted in order to institutionalize the observatory and create sustainability. The purpose of this body would be the coordination of stakeholders (including the private sector), in order to agree on rules and regulations, define policies and procedures, and evaluate their implementation.

\section{Next steps}

1. undertake a stakeholder analysis in countries to build a basis for multi-stakeholder platforms;

2. involve academic institutions in establishing research agendas for strengthening health workforce observatories, and the use of information for decision-making and policy formulation.

\section{Recommendations}

\section{To Member States}

1. perform evaluation for the effectiveness and possible expansion of datasets and indicators for HRH observatories;

2. perform mapping and assessment of data sources and use of health workforce information;

3. review NHWAs and identify further indicators specific to their context, if needed.

\section{To WHO}

1. establish a communication forum;

2. coordinate / conduct capacity building activities for data analysis, research methods and development of policy briefs.

\section{References}

1. WHO Regional Office for the Eastern Mediterranean (WHO/EMRO). Roadmap of WHO's work for the Eastern Mediterranean Region 2017-2021. Cairo: WHO/EMRO; 2017 (http://applications.emro.who.int/docs/EMROPUB_2017_19695_EN.pdf?ua=1, accessed 9 August 2018).

2. United Nations. Goal 3: ensure healthy lives and promote well-being for all at all ages. New York: United Nations; 2015 (https:// www.un.org/sustainabledevelopment/health/, accessed 9 August 2018).

3. World Health Organization. Sustainable Development Goal 3: Health. Geneva: World Health Organization; 2016 (http://www. who.int/topics/sustainable-development-goals/targets/en/, accessed 14 August 2018).

4. World Health Organization. Global strategy on human resources for health: workforce 2030. Genevea: World Health Organization; 2016 (http://apps.who.int/iris/bitstream/handle/10665/250368/9789241511131-eng.pdf;jsessionid=FD72ED37C7640FC41A1B5F52479820C9?sequence=1, accessed 9 August 2018). 
5. Sixty-ninth World Health Assembly. Global strategy on human resources for health: workforce 2030 (WHA69.19). New York: World Health Assembly; 2016 (http://apps.who.int/gb/ebwha/pdf_files/WHA69/A69_R19-en.pdf, accessed 9 August 2018).

6. WHO Regional Office for the Eastern Mediterranean (WHO/EMRO). Framework for action for health workforce development in the Eastern Mediterranean Region 2017-2030. Cairo: WHO/EMRO; 2017 (http://www.emro.who.int/images/stories/hrh/Strategic_framework_for_health_workforce_development_MAY_2017_3.pdf, accessed 9 August 208).

7. World Health Organization. Health workforce. Geneva: World Health Organization; 2018 (http://www.who.int/healthsystems/ topics/workforce/en/, accessed 9 August 2018).

8. WHO Regional Office for the Eastern Mediterranean (WHO/EMRO). Summary report on the meeting on health workforce observatories in the Eastern Mediterranean Region. Cairo: WHO/EMRO; 2017 (http://applications.emro.who.int/docs/IC_Meet_ Rep_2018_EN_16777.pdf, accessed 9 August 2018). 